\title{
Ductal Breast Carcinoma In Situ and Invasive Lobular Carcinoma
}

National Cancer Institute

\section{Source}

National Cancer Institute. Ductal Breast Carcinoma In Situ and Invasive Lobular

Carcinoma. NCI Thesaurus. Code C6939.

A breast carcinoma characterized by the presence of a ductal carcinoma in situ component and an invasive lobular carcinomatous component. 